\title{
Para assistir aos vilões Disney: abjeção e heteronormatividade em "A Pequena Sereia"
}

\section{How to watch the Disney villains: abjection and heteronormativity in "The Little Mermaid"}

\author{
Caynnã de Camargo Santos ${ }^{1}$, Luís Paulo de Carvalho Piassi²
}

\begin{abstract}
Resumo
Compreendendo a cultura midiática como um dos principais espaços contemporâneos de (re)produção de sentidos acerca dos mais variados âmbitos da vida social, a partir dos quais são estruturados procedimentos de controle e exclusão de corpos, ideias e comportamentos, o presente trabalho objetiva desvelar e analisar criticamente a sutil estratégia discursiva empregada em filmes de animação dos Estúdios Disney, estratégia essa que cumpre em reiterar a "normalidade" das formas de identificação por gênero hegemônicas a partir da abjeção de identidades desviantes. Para tanto, empreendemos uma análise sociocultural da vilã Úrsula, de A Pequena Sereia (1989), valendo-nos de aspectos metodológicos próprios à semiótica e à Análise Crítica do Discurso. Mediante uma leitura informada pelos Estudos Culturais e pela Teoria Queer, observamos que o padrão de representação mobilizado na animação veicula uma implícita avaliação negativa das formas de ser e agir que frustram o binarismo heteronormativo, associando-as inequivocamente com crueldade e ganância.
\end{abstract}

Palavras-chaves: Cinema. Disney. Vilão. Heteronormatividade. Drag.

\begin{abstract}
Understanding media culture as one of the main fields where processes of (re)production of meanings attributed to various aspects of social life take place, from which are structured procedures of control and exclusion of bodies, ideas and behaviors, this study aims to unveil and critically analyze the subtle discursive strategy recurrently used in Disney Studios animated films, strategy that consists in reiterating the normality status of hegemonic forms of gender identification by attaching negativity content to deviant identities. Therefore, we undertake a socio-cultural analysis - freely mobilizing methodological aspects of semiotics and Critical Discourse Analysis - of the gender performances of Ursula, the villain of The Little Mermaid (1989). We observe that the representation pattern mobilized in the animation conveys an implicit evaluation of the ways of being and acting that frustrate the binary gender norms, unequivocally associating them with cruelty and greed.
\end{abstract}

Keywords: Cinema. Disney. Villain. Heteronormativity. Drag..

${ }^{1}$ Doutorando em Sociologia pela Universidade de Coimbra (Portugal). E-mail: caynna.santos@usp.br

2 Doutor em Educação pela Faculdade de Educação da USP, Livre-Docente em Artes, Cultura e Lazer pela Escola de Artes, Ciências e Humanidades da USP . Orientador do programa de pós-graduação em Educação da Faculdade de Educação USP e do programa Estudos Culturais da EACH/USP. 


\section{Introdução}

Vemo-nos hoje envoltos em um mundo fartamente povoado por imagens ancoradas em mecanismos de reprodução técnica. Dos pequenos dispositivos celulares que nos acompanham durante a quase totalidade de nossos dias, às grandes telas cinematográficas às quais nos dirigimos em nossos raros momentos de lazer com objetivos de evasão ou fruição estética, passando pelos medianos dispositivos televisivos e peças publicitárias em espaços públicos, somos constantemente alvejados, interpelados e atravessados pela reprodução imagética, contexto que parece justificar o emprego da expressão "cultura do ecrã" (DONNAT, 1994, p. 284). O papel da imagem apresentada a nós em suporte técnico enquanto elemento nodal da tessitura de nossa experiência cotidiana contemporânea é tal que só nos damos conta de sua (oni)presença quando esta repentinamente se ausenta (geralmente em decorrência de falhas técnicas e durante espaços de tempo quase imperceptíveis), deixando-nos desconfortavelmente diante de uma realidade exterior à tela.

Se, em um período histórico anterior, a imagem se viu como refém de uma realidade exterior a si, inserida em um regime moderno de analogia, segundo o qual sua função estaria restrita a mimetizar uma materialidade sobre a qual pouco poderia atuar, com o desenvolvimento, no último século, de técnicas cada vez mais complexas dedicadas à sua produção e difusão, observou-se uma transformação radical de seu estatuto. Os novos dispositivos tecnológicos produzem e distribuem em grande escala imagens que simulam a realidade com um nível de harmonia e rigor nunca antes visto. Em meio a esse processo de incorporação da aparência do real, alguns críticos afirmam que a imagem se coloca no lugar de sua antiga matriz, realizando o real como signo, isto é, constituindo simulacros. Nesse novo contexto, organizado sob a égide do que Baudrillard (1983) chamará de "reino do signo", a imagem autotélica potencializa sua agência sobre o processo de significação da realidade social, ou seja, ela agora não apenas faz ver um real que pouca (ou nenhuma) fidelidade conserva em relação a um referente exterior a si, como faz crer nessa construção simbólica como sendo "o verdadeiro real" (BOURDIEU, 1997, p. 28).

Talvez a forma de expressão artística visual que melhor sintetiza tal potencial imagético de criar universos simbólicos que parecem se fundir com a realidade exterior seja o cinema. O enunciado fílmico caracteriza-se como uma forma de manifestação cultural capaz de fascinar grandes públicos ao promover, por meio da união entre imagem, som e movimento, uma experiência sensorial, narrativa e estética que replica em muitos níveis os modos naturais de conhecimento direto do mundo. O potencial cinematográfico de mobilização das principais faculdades perceptivas de seus espectadores funda sua particularidade e centralidade em meio às demais formas artísticas: a imagem cinematográfica tem o poder de criar "efeitos de real" e, por conseguinte, "efeitos no real". No decorrer do século XX, com seu desenvolvimento técnico e consolidação enquanto fenômenos de relevância sociológica e artística, as produções cinematográficas se tornaram, além de produtos de entretenimento extremamente presentes na vida cotidiana, práticas culturais capazes de oferecer expressão imagética a um marcadamente heterogêneo - e muitas vezes conflitante - conjunto de valores e cosmovisões, figurando assim como instâncias (re)construtoras de sentidos atuantes no âmbito intrasubjetivo, interpessoal e em termos das relações estabelecidas entre indivíduos e suas vigentes condições de existência. Seria extremamente contestável a afirmação de que os Irmãos Lumière, ditos "Pais do cinema" e adeptos de uma concepção realista em relação à sua invenção, poderiam ter imaginado em algum momento (mesmo em seus sonhos mais extravagantes) que a linguagem criada por eles não só sobreviveria ao século $\mathrm{XX}$, transmutando-se em diversos novos formatos, como alcançaria uma relevância socioeconômica-cultural minimamente comparável àquela atribuída ao cinema na contemporaneidade. 
Apesar da grande atenção dada por pesquisadores às produções cinematográficas em geral desde os primórdios do cinema, os filmes infantis de animação longa-metragem, um dos gêneros cinematográficos de maior aceitação por parte do grande público, permaneceram durante muito tempo relegados a subprodutos da indústria cultural, sendo assim marginalizados por estudiosos da cultura. A partir de propostas inovadoras tais quais as da tradição intelectual dos Estudos Culturais, que propõe uma visão mais democrática acerca da cultura, ressaltando a importância da análise das mais variadas formas de expressão cultural e produção simbólica visando à compreensão dos complexos fenômenos vivenciados pelas sociedades contemporâneas (CEVASCO, 2003), tal formato cinematográfico passou a despertar atenção do meio acadêmico, transformando-se em objeto de pesquisa científica. Essa virada deveu-se em grande medida ao reconhecimento da importância dos filmes infantis de animação enquanto instrumentos de educação moral não-formal (SABAT, 2003), capazes de veicular discursos ideológicos acerca de padrões estéticos e de conduta, construindo assim o senso de normatividade social. Ou seja, por essa nova visada tais discursos midiáticos atuariam de forma a apresentar persuasivamente ao público infantil os padrões aceitos e não aceitos em uma determinada especificidade histórica e cultural.

$\mathrm{O}$ presente artigo versa sobre o processo de construção de significados e valorizações de gênero e de sexualidades segundo modelos dualistas e restritivos nos discursos cinematográficos norteamericanos endereçados ao público infantil. Entendemos aqui as performances de gênero socialmente aceitas e a heterossexualidade não como elementos naturais, mas como condições cultural e ideologicamente construídas e sóciohistoricamente contingentes, sendo que diferentes mecanismos - entre eles os discursos religiosos, médicos, científicos e midiáticos -, são utilizados continuamente na tentativa de garanti-las como condições normativas. Em meio a tantas tecnologias do gênero (LAURETIS, 1994), tomamos como objeto de análise os filmes de animação longametragem dos estúdios Disney, nos debruçando sobre o filme A Pequena Sereia (1989), de modo a analisar como neste se dá a produção da abjeção relacionada a corpos e condutas que frustram as expectativas heteronormativas mediante a construção arquetípica de um "vilão desviante" (SANTOS, 2015).

Para tanto, a título de aporte metodológico mobilizamos a abordagem da semiótica discursiva de linha francesa, derivada dos trabalhos de Greimas (1973), em conjunto com determinados elementos teóricos próprios da linha de pesquisa convencionalmente chamada de Análise Crítica do Discurso, que relaciona o texto à sua exterioridade, ou seja, às condições e contextos sociais, históricos e ideológicos de produção de sentido. No âmbito dos Estudos Culturais, Jameson (2008) tem situado a semiótica de linha francesa, pontuando seus alcances e limitações. Buscamos, portanto, a partir da articulação das duas perspectivas teóricas (uma voltada para o texto em si e outra privilegiando os condicionantes históricos, políticos e culturais do objeto da Linguística), promover uma análise sociocultural crítica do texto em questão, orientando nossos esforços não apenas para a elucidação dos componentes narrativos ou iconográficos do filme, mas também para a análise das condições sóciohistóricas de emergência de tal enunciado.

A escolha das animações infantis longametragem como objeto de análise justifica-se devido à importância destas enquanto textos culturais que veiculam e constroem significados, caracterizandose assim como espaços perpassados pelas relações de poder, onde se materializam "lutas e contestações dos processos de significação produzidos pelo conhecimento hegemônico" (SABAT, 2003, p. 27). Como afirma Giroux (1995), tais artefatos culturais têm produzido durante gerações representações que asseguram imagens, identificações e desejos a partir dos quais os espectadores produzem a si próprios e suas formas de interação social, em meio 
a um processo que o autor chama de "pedagogia da inocência”. Henry Giroux acentua ainda o papel das animações enquanto instrumentos de aprendizagem persuasiva junto ao público infantil. Para ele,

É desnecessário dizer que a importância dos filmes animados opera em muitos registros, mas um dos mais persuasivos é o papel que eles exercem como novas "máquinas de ensinar". [...] Esses filmes inspiram no mínimo tanta autoridade cultural e legitimidade para ensinar papéis específicos, valores e ideais quanto locais mais tradicionais de aprendizagem, tais como escolas públicas, instituições religiosas e a família (GIROUX, 1995, p. 50).

Acreditamos que, na contemporaneidade, há uma clara ampliação das arenas de prática dos processos de constituição de individualidades e coletividades, relações de poder assimétricas e mobilização de versões específicas de passado, presente e futuro, para além dos âmbitos políticos, econômicos e pedagógicos em suas definições stricto sensu. Em meio ao cenário das intensas "guerras culturais" (HUNTER, 1991), a cultura popular constitui um dos espaços centrais onde as lutas por representação e (re)conhecimento estão sendo travadas, caracterizando-se como um campo altamente disputado e cobiçado por grupos dominantes em seu esforço para assegurar sua hegemonia cultural.

Nosso foco de estudo recai especificamente sobre as performances de gênero da antagonista do filme em questão, compreendendo que as formas de ser entendidas como normais são determinadas pelo contraste com aquelas tomadas como desviantes e, nesta medida, destas últimas dependentes. Sendo assim, o trabalho parte do entendimento de que qualquer processo de produção e reafirmação de um determinado modelo identitário que se pretende hegemônico implica, mais que a apresentação do "Mesmo", ou seja, o socialmente valorizado, a constituição de um "Outro", de um espaço de abjeção inabitável - porém estrategicamente habitado que é convocado constantemente pela norma de modo a cumprir a função, em relação a esta, de seu "exterior constitutivo" (BUTLER, 1993). O gênero é compreendido aqui enquanto um contínuo processo de normatização que tem como um de seus principais efeitos e instrumentos a produção de excluídos. Analisaremos, portanto, como se dá a produção de tal codificação do "Outro" - os corpos e identidades que não podem existir dentro de uma matriz de inteligibilidade heteronormativa - na figura da vilã Úrsula, de A Pequena Sereia.

No tocante à perspectiva teórica que adotamos, retemos dos estudos feministas e queers o compromisso em desnaturalizar os modelos restritivos de masculinidade e feminilidade hegemônicos, evidenciando seu caráter regulatório e as assimetrias de poder que estes legitimam. Dos Estudos Culturais, mantemos a ênfase crítica com que estes abordam a "cultura da mídia" (KELLNER, 2001). Informado pelos Estudos Culturais, nosso esforço investigativo propõe desenvolver, mais que uma análise textual, uma leitura política e social do discurso cinematográfico objeto de nosso interesse.

\section{Foucault, Poder e Sexualidade}

Um dos fundamentos teóricos do presente artigo é a compreensão do gênero como, em grande medida, um efeito de práticas discursivas, que se dá por meio do desdobramento de variados mecanismos, entre os quais o cinema. Tal posicionamento, em sua versão mais linguisticamente radicalizada, é característico de um corpo teórico que se organiza sob a alcunha de Teoria Queer. De fato, é problemático afirmarmos sem ressalvas que há uma única "Teoria Queer", cujos fundamentos teóricos são consensualmente partilhados por um conjunto coeso de estudiosos. Assemelhando-se a um campo gravitacional, mais que a uma disciplina acadêmica rigidamente delimitada, o "projeto" queer tem entre suas poucas características definidoras a crítica a modelos de gênero e sexuais hegemônicos, atentando para as marginalidades e invisibilidades que estes constroem, e a importância atribuída a alguns poucos referenciais teóricos, que são partilhados por muitas e muitos autoras e autores 
ligadas(os) a tal "empreendimento" crítico. Os trabalhos de Michel Foucault, por sua vez, figuram como alguns desses raros referenciais comuns.

Tendo em mente os objetivos do presente artigo, em meio à vasta e rica produção teórica de Michel Foucault, acentuamos dois pontos de nosso especial interesse, a saber: (1) a visada antiessencialista proposta por Foucault sobre o corpo sexuado, que se expressa no modo particular como o pensador francês entende pilares de nossa identificação enquanto sujeitos (em especial o sexo e a sexualidade) em sua inelutável historicidade, enquadrando-os como efeitos de uma articulação complexa e sócio-historicamente contingente entre poder, discurso e conhecimento e (2) sua particular compreensão das dinâmicas de poder que tomam parte na modernidade enquanto processos que se valem da mobilização de um amplo e heterogêneo leque de tecnologias sociais, orientado para a constituição e simultânea regulação de corpos e práticas, segundo um regime de normalização. Em síntese, da intersecção dessas duas vertentes gerais do pensamento foucaultiano, emergem alguns fundamentos político-conceituais extremamente influentes para grande parte do movimento teórico que se desenvolve desde o final da década de 1980 no bojo dos debates sobre gênero (e com o qual estabelecemos aqui um diálogo direto), que busca situar o gênero como uma categoria plástica (PRECIADO, 2014) e performativa (BUTLER, 2008) - em detrimento de visões naturalizantes - que se constituiria principalmente através da proliferação de discursos, objetivando a regulação de corpos e práticas segundo um imperativo binário.

Uma afirmação fundamental do projeto teórico do pensador francês é a de que "o poder produz saber" (FOUCAULT, 2010, p. 30); mediante a produção de saberes, o poder, concomitantemente, subjetiva e assujeita indivíduos, posicionandoos em espaços específicos dentro de um quadro definido por um determinado "regime de verdade". Desse modo, Foucault questiona a antinomia entre saber e poder, que tem influenciado grande parte do pensamento ocidental desde Platão, compreendendo que tais dimensões aparentemente opostas funcionam conjuntamente, em uma dinâmica de inter-implicação que ele nomeia de "poder-saber". Segundo o autor, "não há relação de poder sem constituição correlata de um campo de saber, nem saber que não suponha e não constitua ao mesmo tempo relações de poder" (FOUCAULT, 2010 , p. 30). Tal posicionamento, que caracteriza o saber como efeito do poder e instrumento para seu exercício, engendra a crítica de Foucault à ideia de poder como fundamentalmente repressivo.

Para Foucault, as formas de exercício do poder vigentes na modernidade ocidental não podem ser entendidas como unicamente negativas, ou seja, atuantes segundo uma lógica de interdição, repressão ou recusa. Em contraposição a tal hipótese repressiva do poder, o autor insistirá no caráter produtivo do fenômeno, localizando entre os séculos XVIII e XIX o período de transição histórica de um modelo jurídico (eminentemente repressivo) para um modelo disciplinar de sociedade, mudança paradigmática expressa pela substituição da lei pela norma como instrumento primário de controle social.

Ainda, enquanto o paradigma jurídico caracteriza o poder como apanágio de determinadas pessoas ou instituições, a ideia de poder disciplinar entende que este transversaliza todos os âmbitos sociais, ou seja, é imanente às mais variadas relações econômicas, políticas, de significação, etc. Dessa forma, Foucault se opõe à representação do poder - exemplarmente expressa pelo célebre modelo de Althusser e seus AIE (Aparelhos Ideológicos de Estado) - que busca encarná-lo e limitá-lo à figura do Estado e seus aparelhos repressivos e ideológicos, tomando-os respectivamente como a fonte soberana de onde emana o poder e seu meio de exercício por excelência. Ressaltando que um dos principais esquematismos a ser evitado quando tratamos do tema refere-se àquele "que consiste em localizar o poder no aparelho do Estado e em fazer do aparelho de Estado o instrumento privilegiado, capital, maior, quase único do poder de uma classe 
sobre uma outra classe" (FOUCAULT, 2000, p. 91), o autor pensa criticamente o poder pela perspectiva dos mecanismos heterogêneos de dominação, que garantem seu exercício regulador fora do domínio político estreitamente definido. Desse modo, a partir do advento de sua perspectiva pós-estruturalista, o poder não pode ser identificado exclusivamente com determinada entidade, mas "está em toda parte" e "provém de todos os lugares" (FOUCAULT, 1999).

Para ilustrar tais proposições teóricas, Foucault irá se voltar para a análise do sexo e da sexualidade. Nesse contexto, afirmar que o poder é um ato produtivo significa que as técnicas de poder exercidas sobre corpos sexuados e suas práticas sexuais, com especial ênfase a partir de finais do século XIX, se valeram fundamentalmente de um modelo produtivo de discursos e saberes, constituindo uma ciência da sexualidade que incita o sexo, ao invés de simplesmente invisibilizá-lo. Essa moderna scientia sexualis produziu uma miríade de sexualidades que, simultaneamente à sua criação, foram dispostas segundo um regime de normalização (que demarca os limites entre o normal e o anormal), em oposição ao modelo jurídico de poder, historicamente anterior, que atuava de modo a promover a separação entre o lícito e o ilícito.

Prova disso é que identidades sexuais que são, na atualidade, largamente reconhecidas como naturais e a-históricas, tais quais a heterossexualidade e a homossexualidade ${ }^{3}$, foram criadas no século XIX pelo discurso médico, com o objetivo de normalizar a primeira e, simultaneamente, patologizar a última, regulando discursiva e institucionalmente corpos e condutas.

É observável nos escritos de Foucault a centralidade atribuída às práticas discursivas em meio a esse processo regulador de multiplicação de identidades "normais" e "errantes". O autor acentua, por exemplo, o surgimento na psiquiatria, na jurisprudência e na literatura, ao final do século XIX, de uma série de discursos sobre a homossexualidade que permitiram o avanço do controle social sobre tal domínio da "perversidade" (FOUCAULT, 1999). Como veremos adiante, é em meio a esse heterogêneo leque de tecnologias sociais do poder que localizamos o cinema, compreendendo-o como uma tecnologia do gênero; isto é, um mecanismo discursivo que atua na produção do masculino e do feminino, no sentido de, tal qual um tentáculo do poder cujo objeto é a própria vida, o corpo e seus prazeres (que Foucault nomeará de "biopoder"), operar regulando corpos e condutas segundo um imperativo heteronormativo

\section{Gênero e Performatividade}

Sob a forte influência do pensamento de Foucault, a filósofa norte-americana Judith Butler propõe uma crítica radical ao modelo sexo/gênero, paradigmático no âmbito dos estudos culturais e feministas até meados da década de 1980, visando trazer definitivamente para o campo discursivo estruturas ditas "naturais" tais quais sexo, corpo, binarismo sexual, etc. Criticando os entendimentos dominantes à época, que partiam da suposição de que haveria uma oposição rígida entre o fato biológico "sexo" e o modo culturalmente determinado de expressão dessa diferença sexual "gênero", Butler (2008) defende que o gênero é, mais que um meio social de atribuição de sentidos aos sexos, um discurso através do qual se cria a ilusão do sexo como propriedade natural dos corpos humanos.

$\mathrm{Na}$ esteira de Foucault, Butler argumenta que o processo de identificação por gênero é sempre um processo de essencialização informado por relações de poder, que funciona no sentido de transformar atos isolados em substância. A partir da citação repetitiva de atos performativos, que se dá na tensão entre agência e constrangimento estrutural, indivíduos constituem a ficção reguladora de existência de corpos sexuados e subjetividades genderizadas prévios à sua produção

Foucault (1999, p. 43) precisa que o ano natalício da homossexualidade é 1870, quando da publicação do artigo de Karl Westphal sobre "sensações sexuais contrárias" nos Archiv für Psychiatrie und Nervenkrankeiten. 
discursiva. Tal dinâmica performativa, porém, não se desenvolve livremente, mas é orientada por uma matriz heterossexual, que busca fixar identidades calcadas no binarismo masculino/feminino. Em outras palavras, a partir da repetição estilizada de atos, cria-se a ilusão de subjetividades ontologicamente marcadas unicamente como masculinas ou femininas.

A partir das colocações de Judith Butler, autora que é comumente apontada como precursora e maior expoente da Teoria Queer, temos que o gênero não pode ser compreendido como algo natural ou biológico, inscrito a priori nas subjetividades. Considerado pelo prisma das dinâmicas disciplinares de poder vigentes na modernidade ocidental, o gênero caracteriza um conjunto de efeitos produzidos em corpos, comportamentos e relações sociais, por meio da mobilização de um amplo grupo de tecnologias sócio-políticas (LAURETIS, 1994).

\section{O Cinema como uma Tecnologia do Gênero}

As tecnologias do gênero (lê-se: o aparato responsável por sua produção; os instrumentos utilizados para fixar performatividades normativas, sem os quais não há o gênero) estendem-se de mecanismos propriamente semióticos a instrumentos técnicos de transformação corporal ${ }^{4}$. No presente artigo, nos debruçamos sobre o papel desempenhado pelas práticas simbólicas em meio ao processo de constituição e simultânea disposição de corpos e condutas segundo uma estrutura de sentidos calcada na diferenciação rígida entre masculino, feminino e perverso. Acreditamos que os meios de comunicação surgidos nos séculos XIX e XX (jornais, rádio, televisão, cinema, internet, etc) desempenham papel fundamental na contínua produção e disseminação do gênero enquanto norma binária e restritiva.
Teresa de Lauretis (1994) acentua a relevância da linguagem cinematográfica enquanto uma tecnologia do gênero. Destacando-se em meio às diversas práticas culturais do ocidente, o aparelho cinemático tem historicamente produzido representações ideológicas do gênero, que cumprem em construir o "feminino" de modo ontologicamente marcado pela opressão patriarcal. Segundo Lauretis (1994), a partir da articulação entre técnicas narrativas e códigos cinemáticos específicos, os filmes têm interpelado indivíduos de maneira a moldá-los e posicioná-los dentro de uma matriz heterossexual. Nesse processo, cuja influência se exerce tanto no nível social quanto subjetivo, a imagem fílmica educa o olhar, ao passo que produz saberes sobre corpos e comportamentos.

Portanto, entendemos que o cinema não se relaciona mimeticamente com uma realidade genderizada que lhe é exterior e preexistente à sua formulação simbólica. Ao contrário, o cinema - tomado enquanto importante tecnologia do gênero - funciona produzindo metáforas performativas, isto é, constituindo as diferenças que alega simplesmente traduzir em termos fílmicos. A principal problemática de nosso interesse é exatamente esse processo de produção fílmica de um modelo de gênero restritivo, que mediante a apresentação persuasiva de padrões de normalidade e desvio, visa a reduzir a multiplicidade de formas de ser e agir ao dualismo masculino e feminino.

\section{A Produção Cinematográfica da Abjeção}

Como toda norma, a construção do modelo binário do gênero tem como conditio sine qua non a produção de sua falha, de um espaço de exclusão habitado pelo "Outro" ao qual as/ os "Normais" (lê-se: aquelas e aqueles que se

\footnotetext{
4 Cabe ressaltar, em consonância com Beatriz Preciado (2014) e sua crítica ao recorrente monismo linguístico-discursivo da Teoria Queer, que não se pode definir como lócus prioritário de produção do gênero as práticas simbólicas, mas sim compreender que este se constitui em permanente diálogo entre o "discursivo" (ex: representações midiáticas) e formas de gestão "material" (ex: bioquímica, cirúrgica) do corpo.
} 
adéquam às categorias e limites impostos pelo sistema hegemônico) continuamente se reportarão para definirem-se contrastivamente.

Derrida (2004) nos mostra que as estruturas de sentido binárias se estabelecem segundo uma dinâmica discursiva de presença e ausência, que organiza significados aparentemente dicotômicos em termos de suplementaridade. Por exemplo, na perspectiva da différance de Derrida, os pólos da oposição heterossexualidade/homossexualidade se relacionam de maneira co-pertinente, uma vez que o termo "heterossexualidade" só pode ser definido em oposição com aquilo que não é, de modo que a homossexualidade mostra-se como parte da constituição lógica e semântica da heterossexualidade (MISKOLCI, 2009). Porém, apesar da interdependência dos termos opostos de nosso exemplo, à homossexualidade é atribuída uma condição de inferioridade ontológica em relação à heterossexualidade hegemônica. $\mathrm{O}$ desconstrutivismo derridadiano, portanto, traz à luz os vínculos subterrâneos entre produção de diferenças binárias e construção de relações de subordinação.

JudithButler(1993) seaprofundanaanálise desse papel constitutivo desempenhado pela falha em relação à norma, no âmbito das performatividades de gênero "normais" e "desviantes". Para a autora, o imperativo heterossexual funciona tal qual uma máquina exclusionária, que garante a legitimidade e a naturalidade de determinadas formas de identificação por gênero a partir de, mais que simplesmente a produção de figuras que correspondem idealmente aos parâmetros hegemônicos de masculinidade e feminilidade, a apresentação de corpos e identidades marginais, que deliberadamente frustram tais expectativas dominantes. Este domínio de "seres abjetos" (KRISTEVA, 1982) caracteriza o exterior constitutivo da norma, que cumpre a função de circunscrever o espaço habitado pelos sujeitos "viáveis", no sentido de inteligíveis, pois harmoniosamente categorizados nos termos do binarismo masculino/feminino. Como coloca Butler (1993), esta zona povoada por corpos “impensáveis, abjetos, invivíveis" constituirá o limite definidor do domínio do sujeito; é efeito do "repúdio sem o qual o sujeito não pode emergir" (BUTLER, 1993, p.3). Sendo assim, temos que "o sujeito é constituído através da força da exclusão e abjeção, que produz um exterior constitutivo do sujeito, um exterior abjeto que está, em última instância, 'dentro' do sujeito como seu próprio repúdio fundante" (BUTLER, 1993).

Como argumentamos anteriormente, diversas tecnologias do gênero tomam parte no processo de produção do masculino, do feminino e das identidades "heréticas", estas últimas necessárias para a edificação da norma binária. A produção de tais corpos e condutas errantes é orientada por um processo de abjeção, isto é, sua formulação discursiva é permeada por teor de negatividade, patologia e inferioridade, o que permite que seja reclamada à norma sua naturalidade e inescapabilidade. A produção do gênero em moldes binários, portanto, implica um processo de estigmatização do vasto espectro das condutas situadas além das fronteiras da heteronormatividade.

O clássico estudo de Vito Russo (1987), The Celluloid Closet, foi pioneiro na análise da representação de corpos e comportamentos transgressores das normativas de gênero e sexualidade no cinema comercial norte-americano. Com base no levantamento de filmes lançados desde 1895 até a década de 1980, Russo constatou três padrões gerais de apresentação de identidades de gênero desviantes em Hollywood: (1) transgressor risível; (2) transgressor solitário/depressivo e (3) transgressor perigoso.

Enquanto os dois primeiros padrões de representação parecem ter "reinado" contextualmente na cinematografia norte-americana (o cross dressing foi amplamente empregado como dispositivo cômico entre as décadas de 1910 e 1920 e, apesar de mais duradoura, a figura do desviante suicida teve seu auge entre as décadas de 1960 e 1970), a mobilização de uma figura genérica de desviante perigoso e assassino foi recorrente em grande parte do século passado. O padrão discursivo 
que relaciona estreitamente desvio das normas de gênero e vilania emerge a partir da segunda metade da década de 1920 (FEJES; PETRICH, 1993) e mantém-se em voga, pelo menos, até a década de 1990. Nesse período, sua presença transversalizou virtualmente todos os genres e subgenres cinematográficos - dos noir das décadas de 1940 e 1950 (DYER, 2002) aos slasher films dos anos 80 (BENSHOFF; GRIFFIN, 2005), passando por produções de grandes nomes da sétima arte, como Alfred Hitchcock (CORBER, 1993).

Por meio da análise que se segue, na qual nos valemos de elementos da semiótica greimasiana e da Análise Crítica do Discurso, evidenciaremos como esse recorrente padrão discursivo também foi mobilizado pelas pretensamente assépticas animações Disney, produções envoltas pelo ethos quase inquestionado de inocência e moralidade que permeia a imagem da Disney Company, um dos maiores conglomerados de entretenimento do mundo e presença paradigmática no cenário da cultura midiática endereçada ao público infantil.

\section{Úrsula: a Vilã Desviante}

A narrativa de $A$ Pequena Sereia é estruturada com base na trajetória da protagonista Ariel. A jovem sereia inicia a trama em um estado de disjunção com seu objeto almejado (ou objeto de valor) independência. Nesse primeiro momento da narrativa a sereia de 16 anos quer se emancipar das regras impostas por seu pai Tritão e tornar-se adulta. Essa desejada independência é expressa por sua vontade de ter pernas (um objeto modal de poder) e conhecimento sobre utensílios e costumes próprios dos humanos (um objeto modal de saber), elementos que a tornariam apta a desbravar o mundo da superfície. Porém, assim que Ariel conhece príncipe Eric, seu par romântico na trama, testemunhamos seus desejos iniciais por autonomia, independência e uma vivência humana sendo instantaneamente suplantados por seu interesse por um papel de esposa, transformação essa que evidencia o engajamento da narrativa a uma perspectiva moralizante que valoriza uma imagem extremamente conservadora e limitada de feminilidade, a partir da qual se entende o matrimônio heterossexual como objetivo final inconteste de qualquer mulher.

Em um segundo momento do filme, temos a apresentação do programa narrativo do anti-sujeito Úrsula, programa este estruturado em torno do objeto almejado pela vilã, o poder. Para conseguir este seu objeto de valor, figurativizado pela coroa e tridente do rei Tritão, a vilã deverá primeiramente dominar Ariel. Dessa forma, Úrsula se engaja em um programa narrativo secundário (ou programa de uso), mediante o qual tentará evitar que Ariel beije Eric, para que assim obtenha controle sobre a sereia e, por fim, torne-se a nova rainha dos mares.

Temos que em meio à trama do filme, Úrsula representa uma ameaça à heteronormatividade por ser um empecilho para que a desejada união entre Ariel e Eric seja consumada. Porém, mais que se opor a uma união heterossexual tradicional, Úrsula personifica uma posição crítica orientada diretamente para as categorias mais fundamentais da estruturação dos gêneros a partir de uma divisão binária.

Tomemos como exemplo de análise a música "Poor Unfortunate Souls", cantada pela vilã em meio a seu esforço para convencer Ariel a assinar o contrato mediante o qual daria sua voz em troca de pernas humanas. Na referida cena, claramente construída como uma rotina de um show drag ${ }^{5}$, Úrsula ensina para Ariel as

\footnotetext{
5 A cena é iniciada com Úrsula em uma espécie de camarim, preparando-se para a apresentação enquanto arruma os cabelos e passa batom. A relevância da teatralização desse primeiro momento, conhecido no meio drag como "montagem", não deve ser subestimada, uma vez que tal etapa caracteriza propriamente o "tornar-se drag", o processo de incorporação do personagem por parte do performer através de mudanças corporais diversas (VENCATO, 2002). Em seguida, já "em cena", a antagonista dança e gesticula de maneira exagerada, mobilizando todos os níveis de sua "linguagem corporal". Em determinado momento, a vilã vale-se de uma espécie de alga, utilizando-a como um boá e emprestando um breve - e cínico - tom dramático ao número musical, enquanto seus tentáculos movimentam-se de modo sincrônico e exuberante.
} 
performances de feminilidade que cumprem com as expectativas do hegemônico "mundo masculino branco" (SELLS, 1995). Em meio às suas lições, a vilã canta:

Úrsula: Terá sua aparência/ seu belo rosto/ E não subestime a importância da linguagem corporal!/ O homem abomina tagarelas/ Garota caladinha ele adora!/ Se a mulher ficar falando o dia inteiro e fofocando/ $O$ homem se zanga, diz adeus e vai embora/ Não vá querer jogar conversa fora/ que os homens fazem tudo para evitar/ Sabe quem é a mais querida? É a garota retraída!/ E só as bem quietinhas vão casar..

Com isso, a vilã orienta a jovem sereia no sentido de demonstrar que a voz - representando a fala, mediação através da qual o indivíduo pode se tornar um sujeito do discurso, falandose, e não exclusivamente sendo falado - é na melhor das hipóteses algo inútil, visto que a feminilidade idealizada pelo sistema patriarcal hegemônico é pautada prioritariamente na linguagem corporal e, em última instância, no corpo feminino. O fato das pernas serem tomadas na trama como "porta de entrada" para o mundo feminino humano demonstra também a aceitação dos dominantes padrões de beleza por parte de Ariel - às custas da mutilação de seu próprio corpo.

Além de afirmar que a feminilidade é baseada majoritariamente na aparência, a performance musical de Úrsula - excessiva e marcadamente teatral - evidencia também que o "ser mulher" é uma categoria dramática, ou seja, trata-se de um conjunto de atos, gestos e atuações, norteado por convenções arbitrárias sócio-historicamente contingentes, se distanciando de noções que definem o gênero como um efeito de uma constituição anatômica específica. Expondo o caráter performativo e imitativo do gênero, a vilã permite que Ariel vislumbre as reais condições de superação das estruturas vigentes que organizam as formas de pensar os limites entre identidades masculinas, femininas e desviantes.
Essa oposição radical às normativas de gênero é claramente observável na construção plástica da personagem, que toma parte no nível discursivo do texto. Sua constituição física materializa uma identidade de gênero altamente desviante: longe dos padrões dominantes de beleza feminina (idealmente representados por Ariel e suas irmãs), Úrsula é uma figura obesa, corpulenta e voluptuosa, beirando o grotesco. Enquanto a metade superior de seu corpo apresenta traços definidos socialmente como pertencentes a mulheres (busto farto, por exemplo), sua metade inferior (tentáculos) não apresenta nenhum marcador visível de gênero, comunicando assim o caráter ambíguo de sua identidade.

Contrastando com a fisionomia jovem da protagonista Ariel, Úrsula aparenta certa idade, ostentando rugas e marcas de expressão em sua face. A estrutura facial da vilã é completamente distinta daquela usualmente atribuída a personagens femininos nos filmes Disney: Úrsula apresenta mandíbula larga, boca extremamente grande e nariz retilíneo (próximo ao formato do nariz do rei Tritão), assim como cabelos curtos e eretos, ao passo que Ariel tem queixo fino, boca pequena e nariz arredondado, além de longos cabelos ruivos. A presença, exclusivamente na vilã, de chamativos acessórios (brincos e colar), unhas longas e batom (ambos em uma nada discreta tonalidade vermelha), cílios particularmente longos, pálpebras pintadas em azul (comunicando uso farto de cosméticos) e um sugestivo vestido decotado contribui para a construção do ar extravagante, dramático e marcado pela artificialidade cômica e desviante de Úrsula. Às suas características físicas, somase a voz rouca e grave da atriz Pat Carroll, se contrapondo às vozes agudas das demais personagens femininas da trama. 
Figura 1 - Caracterização facial de Ariel e Úrsula

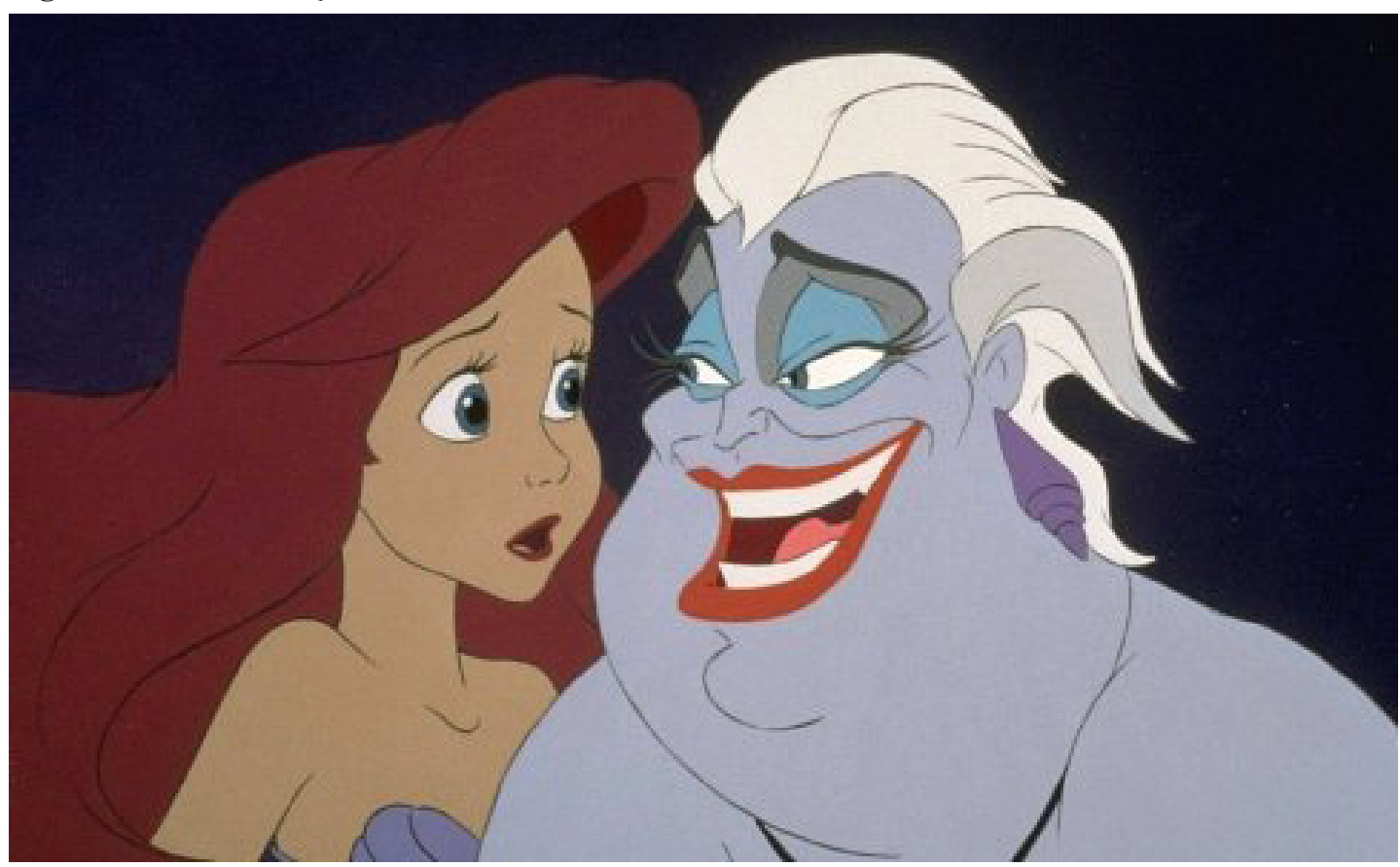

Fonte: A PEQUENA... (1989).

Os movimentos corporais da antagonista caracterizam uma clara oposição ao padrão gestual de Ariel, principal personagem feminina do filme. Enquanto a pequena sereia mobiliza gestos contidos e suaves, Úrsula movimenta-se de modo expansivo e exagerado. Sua gestualidade extravagante é potencializada por seus tentáculos, que funcionam como oito mãos a somar com seus já extremamente expressivos braços. É interessante notar que, ao parar em determinada posição, a vilã posta seus membros de modo estratégico e altamente simbólico, como se tivesse consciência da perspectiva filmica e posasse para a câmera. Em outras palavras, podemos afirmar que seu comportamento não-verbal parece replicar estereótipos amplamente difundidos de feminilidade, o que acaba por instaurar uma dissonância entre um corpo que não se adequa harmoniosamente a nenhuma das tradicionais categorias binárias e uma atuação parodística do feminino.

Todos os elementos aqui apontados permitem que aproximemos a performance de gênero da personagem em questão a uma performance drag. Drag Queens tomam como a tônica de suas identidades (ou pós-identidades) a instabilidade e o contínuo trânsito entre os gêneros, utilizando do humor, do exagero e da ironia para evidenciar o caráter performativo e limitado das categorias binárias hegemônicas. Guacira Louro (2004, p. 21), ao descrever a figura drag, parece sintetizar a multifacetada identidade de Úrsula:

\begin{abstract}
A drag escancara a construtividade dos gêneros. Perambulando por um território inabitável, confundindo e tumultuando, sua figura passa a indicar que a fronteira está muito perto e que pode ser visitada a qualquer momento. Ela assume a transitoriedade, ela se satisfaz com as justaposições inesperadas e com as misturas. A drag é mais de um. Mais de uma identidade, mais de um gênero, propositadamente ambígua em sua sexualidade e em seus afetos. Feita deliberadamente de excessos, ela encarna a proliferação e vive à deriva $[\ldots]$
\end{abstract}

A partir de uma exteriorização exagerada das características culturalmente atribuídas ao feminino, Úrsula constrói uma identidade provocativa que remete, de modo marcadamente complexo e caricato, ao estereótipo de femme fatale, em particular no concernente à sua sexualidade. $\mathrm{O}$ caráter transitório que, como afirma Louro (2004), é definidor das performances drag, é claramente representado por 
Úrsula quando a mesma se transforma em Vanessa, uma versão morena de Ariel. Mascarando-se temporariamente como uma figura que se adequa aos ideais de feminilidade hegemônicos, a vilã evidencia a natureza imitativa e fugaz das identidades que assume, afirmando sua capacidade de ser "mais de um".

Nossa leitura da performance de gênero desviante de Úrsula sob a luz da noção de drag é corroborada quando buscamos informações concernentes às inspirações de seus criadores. Segundo Putnam (2013), Ruben Aquino, diretor de animação responsável pela vilã, assumiu em entrevistas que a imagem de Úrsula foi baseada na figura da icônica drag queen Divine. Vivida pelo ator norte-americano Glenn Milstead, Divine tornou-se a mais reconhecida drag queen dos anos 80 , famosa por seus filmes e peças de teatro que abusavam do estilo trash, obsceno e grotesco. Além da incontestável semelhança visual entre Divine e Úrsula, é possível afirmar que a persona da antagonista animada como um todo foi baseada em grande medida na drag queen criada por Glenn Milstead, em especial seus trejeitos e maneirismos ${ }^{6}$.

Figura 2 - Divine e Úrsula

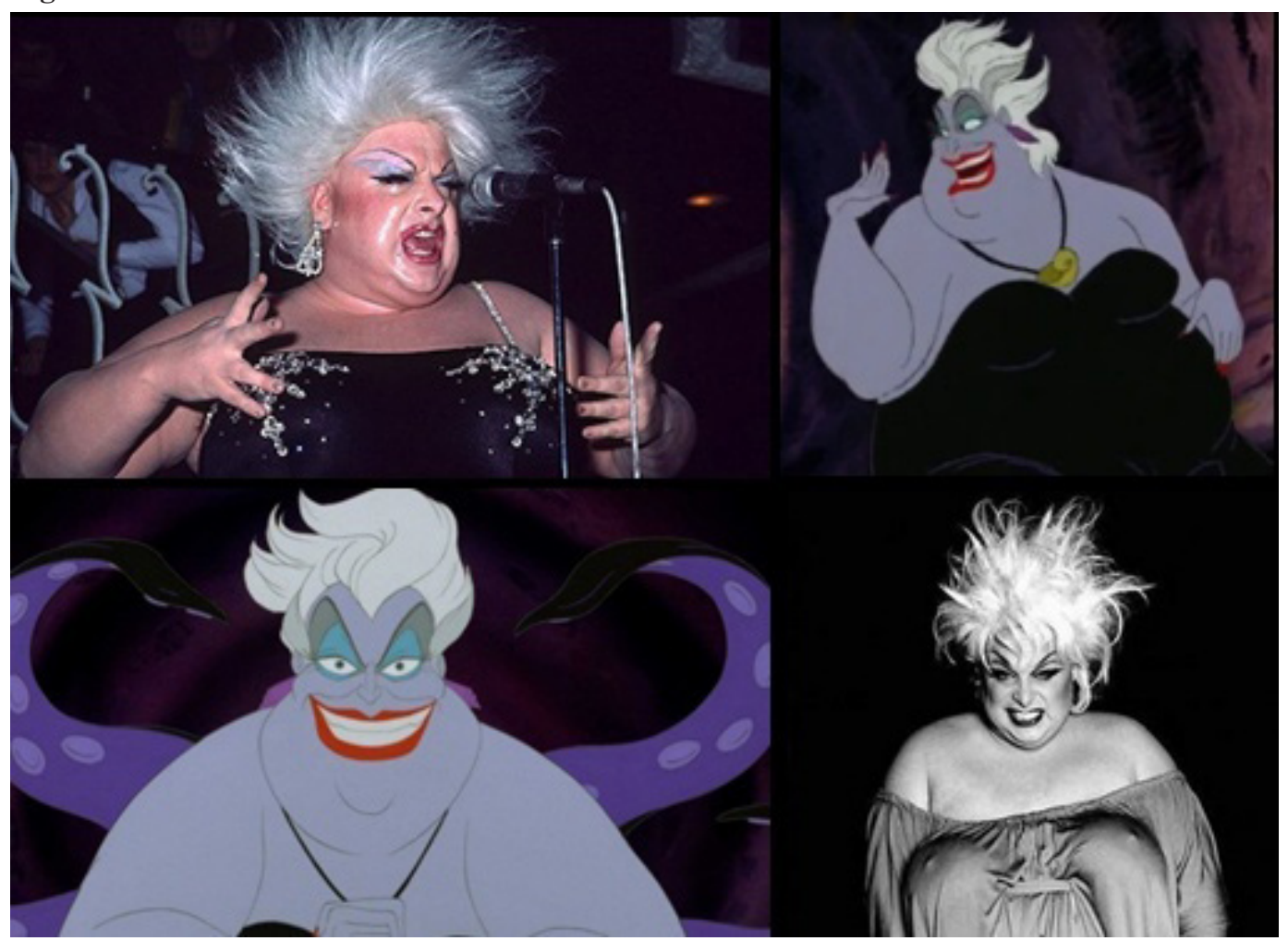

Fonte: Montagem elaborada pelo autor ${ }^{7}$

Segundo Judith Butler(2008), a performance drag parodia o modelo expressivo de gênero e a ideia de uma verdadeira identidade masculina ou feminina.
Nesse sentido, Úrsula desestabiliza exemplarmente o gênero, revelando-o enquanto um construto social. Ao dirigir-se a Ariel em seu número musical

6 A título de curiosidade, é interessante notar que Úrsula, quando metamorfoseada em Vanessa, canta em frente ao espelho (na versão original da canção): "What a lovely little bride I'll make / My dear, I look divine [...]", talvez fazendo uma breve referência à drag queen que lhe serviu de modelo.

7 As imagens de Divine estão disponíveis em: < https://goo.gl/4KI9WG > e < https://goo.gl/WtwcSA > Acesso em: 07 abr. 2015. 
"Poor Unfortunate Souls", desvelando que o gênero nada mais é que uma construção performativa, que mobiliza sentidos a partir da constante repetição de atos e, por conseguinte, reconhecendo que tal noção não se trata de uma categoria natural, a vilã se torna um perigo por poder potencialmente desviar a bela sereia da anteriormente inevitável aliança com o modelo de gênero dominante. Como assinala Laura Sells (1995), as lições da antagonista sobre feminilidade oferecem uma importante posição por meio da qual Ariel poderia resistir às imagens rigidamente delimitadas e patriarcais de mulher. Essa subversão radical, afronta sem precedentes aos "bons-costumes" tão defendidos pela Disney, só poderia ser respondida com uma punição equivalentemente extrema e exemplar, de forma a salvaguardar as fronteiras do sistema heteronormativo.

É o que observamos ao final do filme. Enquanto Ariel é assimilada idealmente pelo modelo hegemônico de gênero ${ }^{8}$, Úrsula morre em uma cena fortemente simbólica, na qual a vilã é perfurada por um fálico mastro de um barco. ${ }^{9}$ Com isso, temos a figurativização da restituição do poder patriarcal sobre a ameaça de desmistificação das categorias identitárias de gênero que sustentam as relações hegemônicas de dominação.

Figura 3 - Morte da vilã Úrsula

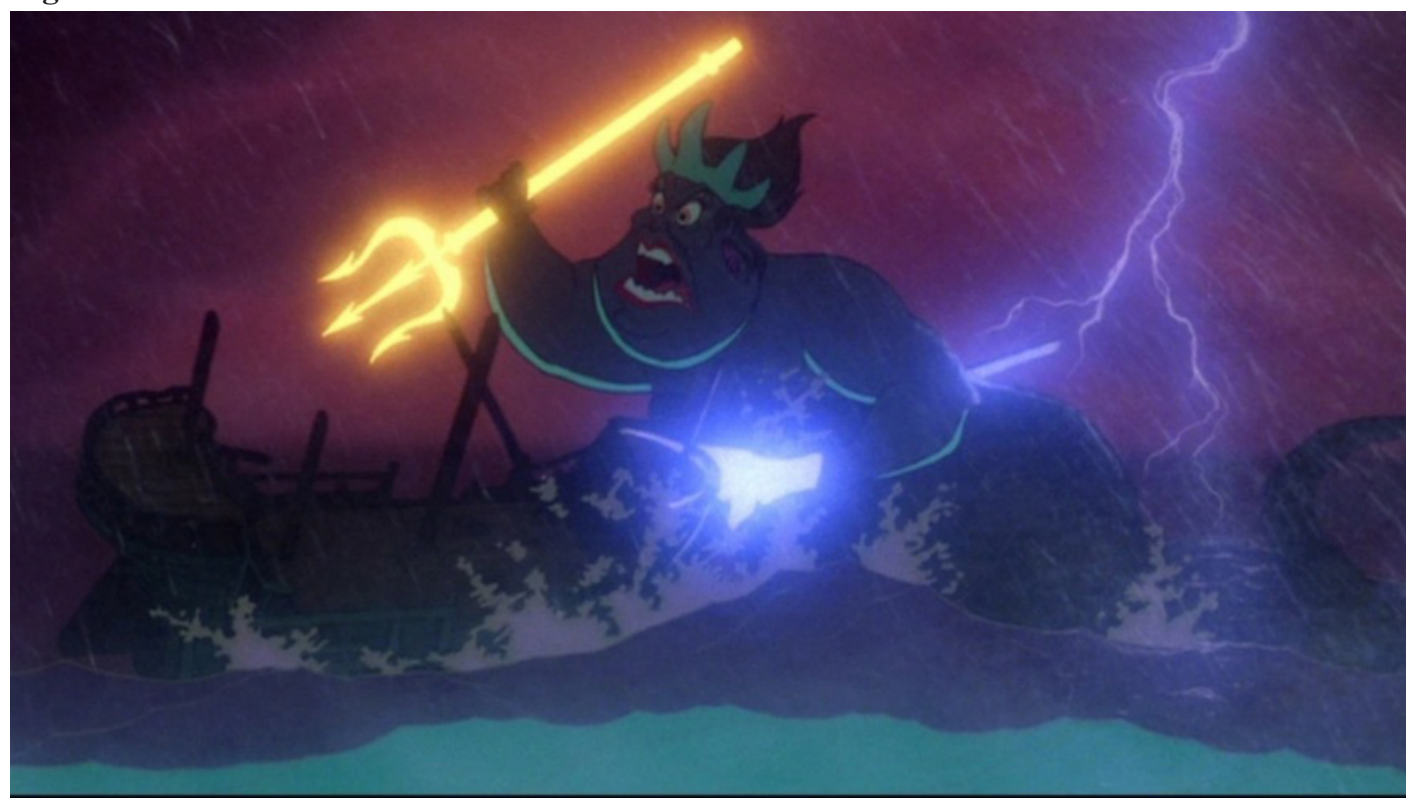

Fonte: A PEQUENA... (1989).

Portanto, podemos observar que Úrsula se heteronormativa tradicional, onde a dicotomia coloca além das fronteiras de binarismos rígidos. masculino/feminino é facilmente reconhecível Essa posição disruptiva da vilã é expressa, por exemplo, por sua condição de exilada do reino de Tritão. No reino impera a lógica patriarcal e desvios mínimos dos papéis de gênero hegemônicos, tais quais a "rebeldia" e a pseudoautonomia da sereia Ariel, são tratados como

\footnotetext{
${ }^{8}$ Ao final do filme, Tritão entrega a mão - e, com isso, a tutela - de sua filha mais nova a príncipe Eric. Tal cena teatraliza a aceitação de Ariel no "mundo masculino branco", às custas de sua inicialmente almejada autonomia.

9 Ainda, poderíamos apontar que, no momento da morte da antagonista, há a instauração de uma determinada correlação semisimbólica entre expressão plástica e plano de conteúdo, que toma parte na oposição entre os tentáculos flácidos da desviante Úrsula e o rígido mastro do barco capitaneado por príncipe Eric
} 
atos isolados e passíveis de punição, porém ainda inteligíveis. Já Úrsula é uma completa outsider, uma criatura que não apenas desafia o patriarcado como também desestabiliza radicalmente as categorias mais basilares do sistema simbólico e da estrutura social do reino.

\section{Considerações Finais}

Vivemos em uma sociedade sobressaturada pelas diferenças entre o masculino e o feminino. Como coloca Lahire (2005, p. 23), o mundo social ocidental contemporâneo atua tal qual "uma espécie de instituição total que socializa de maneira permanente os indivíduos em tais diferenças". Temos argumentado que essas categorias mutuamente excludentes e exaustivas não são fatos naturais ou biológicos, mas construtos socioculturais que, para serem produzidos, dependem de um conjunto heterogêneo de aparatos, que variam de dispositivos técnicos e farmacológicos a práticas discursivas.

O objetivo geral do presente artigo foi analisar como se dá a produção do imperativo binário masculino/feminino através da construção discursiva da abjeção relacionada a corpos e condutas desviantes. Para tanto, nos debruçamos especificamente sobre o processo de (re) constituição cinematográfica do arquétipo de "vilão desviante" na figura de Úrsula, antagonista do filme $A$ Pequena Sereia. ${ }^{10}$

Em uma primeira aproximação, o fato dos estúdios Disney apresentarem no filme em questão uma personagem que marcadamente subverte as barreiras rígidas dos gêneros poderia ser entendido como uma atitude progressista. Ao apresentarem tais identidades, seus filmes estariam não só retratando a realidade social de modo mais verídico e diversificado, como atuariam de forma a familiarizar o público infantil com tais tipos de identificação que fogem à lógica heteronormativa binária. Em outras palavras, seria um modo de reconhecimento discursivo da possibilidade de existência de posições de sujeito que vão além do normativo.

Porém, essa leitura é logo desacreditada ao observarmos a forma como tal "reconhecimento" se dá. A partir do momento em que as qualidades desviantes são aparentes exclusivamente em um personagem mau, temos um processo de estigmatizaçãoquefuncionacomopartedeumesforço mais amplo de normatização de comportamentos. A transgressão está inscrita em um corpo abjeto, no vilão. Mau por natureza e aparentemente irretratável, suas atitudes são a definição do que não deve ser seguido, caso se queira ter uma posição respeitável no meio social. Ao invés de reconhecimento enquanto formas possíveis de performances que frustram as expectativas do senso comum, há uma condenação discursiva das mesmas desde o início. Como aponta Putnam (2013, p. 149), a Disney, ao criar unicamente personagens malignos como transgressores, constrói uma avaliação implícita dessas formas de ser e agir alternativas em relação ao gênero, inequivocamente associando-as com crueldade, egoísmo, brutalidade e ganância. Neste sentido, aspectos como imoralidade, ardil e sadismo são apresentados nos filmes como características inerentes a indivíduos cujas identidades de gênero não se conformam às normas sociais.

Nesse processo, a função ideológica do desviante (o vilão)é ajudara definir e reforçaro que é normativo. Como coloca Velho (2003), um determinado grupo social ou um conjunto de práticas e ideias só pode ser rotulado como bom, desejável e moral após a construção de figuras opostas, que possam ser julgadas como ruins, indesejáveis e imorais. As definições de bom e mau são dependentes uma da outra, se estabelecendo contrastivamente. Desse modo, a apresentação de identidades de gênero desviantes nas animações Disney não caracteriza

10 Para uma discussão mais aprofundada e análises de demais produções da Disney nas quais o arquétipo de "vilão desviante" também se faz presente. Para tanto, ver Santos (2015). 
uma falha do sistema heteronormativo em seu esforço para manter o controle. Ao contrário, figura como um fator necessário para que se possa reiterar a normalidade de determinados grupos e práticas e, simultaneamente, desvalorizar outros.

Cabe salientar que no texto fílmico analisado a vilã é severamente castigada devido a suas formas de ser "reprováveis" (Úrsula é perfurada por um mastro no desfecho da história). Nesse sentido, percebemos uma implícita evocação da justeza de transgressores serem penalizados, entendendo que o restabelecimento moralizante da tradição através da violência é uma ação necessária para o mantimento das estruturas simbólicas e sociais hegemônicas.

Outro elemento a ser acentuado diz respeito ao fato do padrão de representação negativa de desviantes das normas de gênero que observamos na animação Disney fazer parte de uma tendência discursiva mais ampla e duradoura no cinema norte-americano, que pode ser reconhecida desde finais dos anos 1920 e, mais claramente, a partir da década de 1940. A mobilização da figura genérica do desviante perigoso e assassino, como já pontuamos, foi extremamente recorrente no cinema hollywoodiano do imediato pós-guerra, mantendose particularmente evidente nos noir dos anos 50 e perdurando pelas décadas subseqüentes com maior ou menor força, culminando nos chamados slasher films dos anos 80. Em comparação com estes últimos, o filme Disney aqui analisado retém a evidente presença do estereótipo de assassino psicótico queer - também observável nas figuras de Scar, vilão de $O$ Rei Leão, e Jafar, antagonista de Aladdin (SANTOS, 2015) - e até mesmo o padrão de punição fálica dos desviantes de gênero (nomeadamente, a morte de Úrsula).

Esse processo de clara estigmatização discursiva dos detentores de identidades de gênero transgressoras ganha novos contornos e sentidos ao situarmos o filme em questão no contexto sóciohistórico do qual este emerge. Reconhecemos na animação o fenômeno de "transcodificação" (KELLNER, 2001) de posições políticas conservadoras largamente difundidas nas mais variadas esferas da vida comum norte-americana do final da década de 1980, contexto marcado pelo "pânico moral" surgido a partir do surto de AIDS. Temos que os mais variados discursos e práticas sociais convergiam à época na crença de que aquele que não se conforma às normas de gênero é mau e representa uma ameaça, posição essa que, apesar de historicamente presente na cultura norte-americana, contava com especial força e visibilidade dada a onda homofóbica vigente no período. A estrutura heteronormativa e a patologização do desviante eram reiteradas incansavelmente na cultura da mídia dos anos 80 e meados dos anos 90, baseando todo um discurso político hegemônico pautado pelas noções tradicionais de família e sexualidade.

Mais que um estudo de caso, o presente artigo configura um esforço que pretende-se motivador de pesquisas futuras que avaliem as produções midiáticas endereçadas ao público infantil pela perspectiva de seu engajamento com discursos e projetos de poder-conhecimento específicos, despindo-as de sua aparência de entretenimento despretensioso. Como acentua Adorno (1951) em Mínima Moralia, a aparência inócua dos discursos dominantes garante a manutenção de suas formas de dominação. Nesse sentido, no decorrer do trabalho tentamos demonstrar sucintamente que no âmbito da cultura midiática orientada prioritariamente às crianças - e na indústria cultural como um todo - não há textos inocentes em sentido absoluto, mas apenas leituras que, infelizmente, insistem em tratá-los enquanto tal.

\section{Agradecimentos}

Os autores agradecem à Coordenação de Aperfeiçoamento de Pessoal de Nível Superior pela bolsa concedida para desenvolvimento da pesquisa de mestrado, da qual decorreu o presente artigo. 


\section{Referências}

A PEQUENA sereia. Direção de Ron Clements, John Musker. Burbank: Wal Disney Company, 1989. 1 DVD (83 $\mathrm{min})$.

ADORNO, T. W. Mínima moralia. Lisboa: Edições 70, 1951.

BAUDRILLARD, J. For a critique of the political economy of the sign. New York: Telos Press, 1983.

BENSHOFF, H. M.; GRIFFIN, S. Queer images: a history of gay and lesbian film in America. Maryland: Rowman \& Littlefield, 2005.

BOURDIEU, P. Sobre televisão. Rio de Janeiro: Jorge Zahar, 1997.

BUTLER, J. Bodies that matter. New York: Routledge, 1993.

BUTLER, J. Problemas de gênero: feminismo e subversão da identidade. Rio de Janeiro: Civilização Brasileira, 2008.

CEVASCO, M. E. Dez lições sobre estudos culturais. São Paulo: Boitempo, 2003.

CORBER, R. J. In the name of national security: hitchcock, homophobia, and the political construction of gender in postwar america. Durham: Duke University Press, 1993.

DERRIDA, J. Gramatologia. São Paulo: Perspectiva, 2004.

DONNAT, O. Les français face à la culture: de l'exclusion à l'écletisme. Paris: La Découverte, 1994.

DYER, R. The culture of queers. New York: Routledge, 2002.

FEJES, F.; PETRICH, K. Invisibility, homophobia and heterosexism: lesbians, gays and the media. Critical Studies in Mass Communication, Annandale, n. 10, p. 396-422, 1993.
FOUCAULT, M. História da sexualidade I: a vontade de saber. Rio de Janeiro: Graal, 1999.

FOUCAULT, M. Microfísica do poder. Rio de Janeiro: Graal, 2000.

FOUCAULT, M. Vigiar e punir: nascimento da prisão. Petrópolis: Vozes, 2010.

GIROUX, H. A disneyzação da cultura infantil. In: SILVA, T. T.; MOREIRA, A. F. (Org.). Territórios Contestados: os currículos e os novos mapas políticos e culturais. Petrópolis: Vozes, 1995. p. 49-81.

GREIMAS, A. J. Semântica estrutural. São Paulo: Cultrix, Edusp, 1973.

HUNTER, J. Culture wars: the struggle to define America. Nova York: Basic Books, 1991.

JAMESON, F. The ideologies of theory. New York: Verso, 2008.

KELLNER, D. A cultura da mídia. Bauru: Edusc, 2001.

KRISTEVA, J. Powers of horror: an essay on abjection. Columbia: Columbia University Press, 1982.

LAHIRE, B. Patrimônios individuais de disposições. Sociologia, Problemas e Práticas, Lisboa, n. 49, p. 11-42, 2005.

LAURETIS, T. A Tecnologia do gênero. In: HOLANDA, H. B. (Org.). Tendências e impasses: o feminismo como crítica da cultura. Rio de Janeiro: Rocco, 1994.

LOURO, G. L. Um corpo estranho: ensaios sobre sexualidade e teoria queer. Belo Horizonte: Autêntica Editora, 2004.

MISKOLCI, R. A Teoria queer e a sociologia: o desafio de uma analítica da normalização. Sociologias, Porto Alegre, n. 21, p. 150-18, 2009.

PRECIADO, B. Manifesto contrassexual. São Paulo: Edições N-1, 2014. 
PUTNAM, A. Mean ladies: transgendered villains in disney films. In: CHEU, J. (Org.). Diversity in Disney films: critical essays on race, ethnicity, gender, sexuality and disability. North Carolina: McFarland \& Company Publishers, 2013. p. 147-162.

RUSSO, V. The celluloid closet: homosexuality in the movies. New York: Harper \& Row, 1987.

SABAT, R. F. R. Filmes infantis e a produção performativa da heterossexualidade. 2003. Tese (Doutorado em Educação) - Universidade Federal do Rio Grande do Sul, Porto Alegre, 2003.

SANTOS, C. C. O vilão desviante: ideologia e heteronormatividade em filmes de animação longametragem dos estúdios Disney. 2015. Dissertação (Mestrado em Filosofia) - Universidade de São Paulo, São Paulo, 2015.

SELLS, L. "Where do the mermaids stand?" Voice and body in the little mermaid. In: BELL, E.; HASS, L.; SELLS, L. (Org.). From mouse to mermaid: the politics of film, gender, and culture. Bloomington: Indiana University Press, 1995. p. 175-192.

VELHO, G. Desvio e divergência: uma crítica da patologia social. Rio de Janeiro: Jorge Zahar Editor, 2003.

VENCATO, A. P. Fervendo com as drags: corporalidades e performances de drag queens em territórios gays da Ilha de Santa Catarina. 2002. Dissertação (Mestrado em Antropologia) - Universidade Federal de Santa Catarina, Florianópolis, 2002. 
